\title{
A RETOMADA DO DESENVOLVIMENTO E A REGULAÇÃO DO MERCADO DO TRABALHO NO BRASIL
}

\author{
Paulo Eduardo de Andrade Baltar ${ }^{*}$ \\ José Dari Krein**
}

\begin{abstract}
O artigo estabelece uma relação entre a dinâmica do capitalismo contemporâneo no Brasil e os desafios para a discussão de uma regulação pública do trabalho. O debate no Brasil considera os seguintes aspectos: 1) as mudanças no capitalismo contemporâneo vêm apresentando implicações desfavoráveis à regulação pública do trabalho e à ação coletiva dos trabalhadores; 2) a retomada do crescimento da economia possibilitou redefinir os termos do debate do trabalho no Brasil; 3) a crise atual coloca em discussão a possibilidade de o Estado ter um papel mais ativo no desenvolvimento da economia; 4) as tendências demográficas vêm aumentando o peso da PEA adulta, o que traz implicações para o funcionamento do mercado de trabalho. As posições se localizam entre dois polos: 1) a defesa de uma estruturação do mercado de trabalho com implicações na qualidade das relações sociais; 2) a afirmação dos negócios, que destaca a necessidade de maior flexibilização na contratação, no uso e na remuneração do trabalho.

PALAVRAS Chaves: Trabalho. Regulação. Economia e desenvolvimento. Flexibilização.
\end{abstract}

\section{INTRODUÇÃO}

As discussões sobre mercado e relações de trabalho no Brasil envolvem velhas e novas questões. As velhas questões referem-se à história do trabalho no país, em que o processo de assalariamento não constituiu um sistema universal de direitos. A proteção social tem sido uma realidade apenas para segmentos da sociedade, dado o excedente estrutural de força de trabalho, o significativo número de trabalhadores sem registro em carteira profissional, o elevado contingente de autônomos sem acesso à seguridade social e a expressiva fração da população ativa trabalhando sem remuneração em negócios de outros membros da família. Ou seja, o mercado de trabalho assalariado é pouco estruturado e a proteção social ainda está em construção. As questões novas do debate sobre trabalho e proteção social decorrem da

* Doutor em Ciência Econômica. Professor Associado da Universidade Estadual de Campinas - UNICAMP.

Cidade Universitária Zeferino Vaz Barão Geraldo. Cep: 13083970 - Campinas - São Paulo - Brasil - Caixa-postal: 6135. pbaltar@eco.unicamp.br

* * Doutor em Economia Social e do Trabalho. Professor da Universidade Estadual de Campinas.dari@eco.unicamp.br forma como o Brasil se inseriu recentemente no processo de globalização e internacionalização das atividades produtivas e de como as mudanças provocadas pela abertura econômica e financeira redefiniram a agenda de discussão sobre mercado e relações de trabalho.

O impacto inicial da abertura da economia sobre o emprego foi muito forte. Devido à crise da dívida externa na década de 1980, o consumo foi contido, o investimento diminuiu, a importação restringiu-se a um mínimo e o país ficou fora da construção das cadeias internacionalizadas de produção de bens manufaturados. Ao abrir-se ao comércio e à finança internacional em um momento de grande interesse por aplicações financeiras em mercados emergentes, o desempenho da economia foi beneficiado, aumentando o consumo e diminuindo a inflação, com forte aumento de importações de bens manufaturados. A valorização da moeda nacional ajudou a baixar a inflação, mas acentuou os efeitos destrutivos da abertura sobre a produção manufatureira doméstica, rompendo elos das cadeias produtivas existentes, e o país continuou fora das principais cadeias internacionaliza- 
das de bens manufaturados. As crises financeiras dos mercados emergentes (México em 1994/1995, países da Ásia em 1997, Rússia em 1998 e Brasil em 1999) agravaram a deterioração do mercado de trabalho, porque levaram ogoverno a estabelecer uma taxa de juros elevada e a conter a atividade econômica.

O aumento do desemprego aberto, a redução do emprego formal, principalmente nas grandes empresas, a ampliação do número de assalariados sem carteira profissional, notadamente nas empresas menores e no serviço doméstico remunerado, a elevação da participação das pessoas ativas no trabalho por conta própria e no trabalho não remunerado, dominaram a agenda de debates sobre mercado e relações de trabalho na década de 1990. A posição de resistir à inserção passiva na globalização, com uma interferência estatal mais firme na economia, para ter uma melhor evolução do emprego e da renda do trabalho foi vencida pela posição que enaltecia os efeitos de uma abertura brusca e indiscriminada para acirrar a competição e promover a eficiência no uso dos recursos existentes. O predomínio dessa posição restringiu a agenda de discussões sobre mercado e relações de trabalho à questão da adaptação das normas e instituições à abertura da economia, sob o argumento de que essas normas e instituições teriam sido construídas para uma economia fechada e estariam prejudicando a incorporação dos efeitos virtuosos da abertura sobre a concorrência e um melhor uso dos recursos.

A abertura comercial e financeira, entretanto, expôs o país às vicissitudes do sistema financeiro globalizado, marcadas pela instabilidade da década de 1990, quando se incorporou os diversos mercados emergentes. A alternância de fortes entradas e saídas de capital perturbou o funcionamento da economia brasileira, motivando intensas flutuações nas taxas de juros e de câmbio, agravando os efeitos da abertura sobre o emprego e a renda do trabalho. Na visão predominante, porém, o mau desempenho do emprego e da renda do trabalho foi atribuído à inadequação das normas e instituições que regem a contratação, o uso e a remuneração da força de trabalho, que não estariam induzindo a um comportamento apropriado de trabalhadores e empregadores, prejudicando os efeitos da abertura e de maior eficiência no uso dos recursos.

Os equívocos desta posição nos debates sobre mercado e relações de trabalho no Brasil tornaram-se evidentes quando a situação internacional ficou mais favorável às exportações, a partir de 2003. O crescimento do PIB levou a um aumento do emprego formal, diminuindo a participação na absorção das pessoas ativas do emprego sem carteira profissional e dos trabalhos por conta própria e não remunerado. Neste quadro de melhora do mercado de trabalho, a queda da inflação foi acompanhada de um aumento do poder de compra da renda do trabalho. Tudo isso ocorreu sem mudanças nas normas e instituições que regem a contratação, o uso e a remuneração do trabalho.

Em um ambiente político mais favorável aos trabalhadores, os efeitos positivos do desempenho da economia sobre o emprego e a renda do trabalho foram ampliados pela valorização do salário mínimo e pela implementação de um amplo conjunto de políticas sociais. Entretanto, as mudanças recentes na organização da produção, que tendem a uma maior desverticalização e flexibilidade, colocam uma série de desafios novos a serem enfrentados pela regulação pública do trabalho. $\mathrm{O}$ equacionamento adequado desses problemas foi prejudicado pelos acontecimentos da década de 1990. O mau desempenho do mercado de trabalho e o quadro político existente enviesou a discussão sobre regulação do trabalho. A crise mundial recolocou a questão da necessidade de interferência estatal para construir uma economia mais sólida e poder ter uma melhor evolução do emprego e da renda do trabalho.

A redefinição da agenda de debates sobre mercado e relações de trabalho no Brasil é o objeto deste artigo. $\mathrm{O}$ texto contém três partes, além da introdução e das considerações finais. Na primeira parte, é apresentado, brevemente, o padrão mais regulado de relações de trabalho dos países desenvolvidos e as alterações que ocorreram no centro do capitalismo, a partir da reorganização da economia 
mundial após a crise da década de 1970. Este quadro de mudanças constituiu um ambiente desfavorável às ações coletivas dos trabalhadores, em consequência da descentralização ${ }^{1}$ e flexibilização das relações de trabalho. A segunda parte aborda as mudanças na economia brasileira a partir da inserção na globalização. Foi nesse contexto que a agenda da descentralização e flexibilização das relações de trabalho foi introduzida no debate nacional. O quadro de crescente desemprego foi agravado pelo aumento da ilegalidade na contratação da força de trabalho. Os termos do debate, então, foram marcados pelo mau desempenho do emprego e da renda do trabalho. A posição que predominou privilegiou a questão das mudanças nas normas e instituições que regem a contratação, o uso e a remuneração da força de trabalho. A terceira parte, finalmente, trata da redefinição dos termos desse debate com a volta do crescimento econômico e melhora dos indicadores do mercado de trabalho. As mudanças na organização da produção colocam desafios para a regulação pública do trabalho, que precisa ser capaz de fazer com que essas novas tendências não resultem em precarização das condições de emprego, permitindo dar continuidade à melhoria dos indicadores do mercado de trabalho.

\section{CAPITALISMO CONTEMPORÂNEO: implica- ções desfavoráveis aos trabalhadores}

As implicações desfavoráveis aos trabalhadores das mudanças observadas no capitalismo desde meados da década de 1970 são ressaltadas pelo contraste com o que se verificou nos países desenvolvidos, especialmente da Europa, ao longo dos anos 1950 e 1960, quando ocorreu um círculo virtuoso de avanços na economia e no social. Nesse círculo virtuoso de avanços econômicos e sociais destacou-se a atuação de estados nacionais, apoiando o desenvolvimento da produção de bens,

\footnotetext{
${ }^{1}$ Descentralização das relações de trabalho em que a determinação das condições de contratação, uso e remuneração do trabalho tende a ser realizada no âmbito das empresas, em detrimento das negociações gerais por setor econômico.
}

a construção de grandes aparelhos de prestação de serviços em áreas como educação, saúde e seguridade social e a constituição de uma regulação pública do trabalho² (Oliveira, 1994).

O desenvolvimento de sistemas nacionais de produção de bens, acarretando aumentos expressivos de produtividade, foi fundamental para viabilizar a ampliação do consumo privado e público de bens e serviços. Nesse avanço dos sistemas nacionais de produção, o comércio com outros países desempenhou papel complementar, acentuando os ganhos de produtividade e mantendo relativo equilíbrio nos aumentos de exportação e importação. Para esse desenvolvimento da produção nacional com equilíbrio no comércio com outros países foi importante a estabilidade, em nível adequado, das taxas de câmbio entre as moedas dos diferentes países (Belluzzo, 2004).

O desenvolvimento da produção de bens e serviços ocorreu com crescente participação dos serviços na absorção de força de trabalho e na apropriação da renda. A construção e utilização dos grandes aparelhos de prestação de serviços sociais (educação, saúde e seguridade social) foram fundamentais para a existência de baixas taxas de desemprego da população ativa nos anos 1950 e 1960 (Gimenez, 2003).

O crescimento do PIB - bem acima do crescimento do emprego - e a ampliação da carga tributária fizeram o aumento da arrecadação dos impostos acompanhar as despesas do Estado, evitando déficit fiscal e aumento da dívida pública.

Além da ampliação do consumo público de bens e serviços, houve aumento do consumo privado. A segurança proporcionada pelo acesso aos serviços públicos, pelo pleno emprego e pelos aumentos no poder de compra da renda do trabalho, apoiado pela regulação pública do trabalho, levaram as famílias a antecipar as compras de bens

\footnotetext{
2 Por regulação pública do trabalho compreende-se que a determinação das regras e normas que regem a relação de emprego é realizada pelo Estado e/ou pela negociação coletiva entre os agentes sindicais de trabalhadores e empregadores. Em contraposição, há a regulação privada, em que a determinação realiza-se pelo mercado ou pelo poder discricionário do empregador (Krein, 2007; Dedecca, 1999).
} 
de consumo, através do endividamento. O baixo nível das taxas de juros e o aumento de renda no ciclo de vida das pessoas facilitaram a ampliação do grau de endividamento das famílias e a manutenção de baixos níveis de inadimplência. A regulação pública do sistema financeiro, procurando preservar baixas taxas de juros, foi fundamental para que os financiamentos, não somente do consumo, mas também da produção e do investimento, ocorressem em moedas nacionais e com prazos e taxas adequadas.

A atuação dos Estados nacionais foi, então, fundamental para o círculo virtuoso de avanços sociais na Europa, depois da Segunda Guerra Mundial. A ordem econômica, constituída depois de Bretton Woods e em meio à guerra fria, permitiu expressivo grau de autonomia de ação aos Estados Nacionais. Na Europa, essa capacidade de ação autônoma do Estado Nacional se materializou positivamente para o avanço econômico e social constatado, porque coalizões políticas domésticas respaldaram aquela atuação, mesmo quando se sucederam governos articulados por diferentes forças políticas (Belluzzo, 2004).

Uma vez completadas as construções dos sistemas nacionais de produção e dos aparelhos de prestação de serviços sociais, os ritmos do investimento e do crescimento do PIB tenderam a diminuir, problematizando a continuidade do círculo virtuoso do pós-guerra. Na culminação dessa onda de crescimento e antes do seu arrefecimento, os protestos sociais, do final da década de 1960, evidenciaram a insatisfação, principalmente, de uma juventude bem mais educada do que a geração anterior, com os valores e padrões de comportamento que se consolidaram em uma sociedade de massa mais regulada e burocratizada. Simultaneamente, houve uma deterioração nas relações entre estados nacionais que levou a uma ruptura da ordem internacional construída a partir de Bretton Woods.

A desaceleração do PIB em meio à crescente desordem internacional, acompanhada do aumento de preços das commodities - destacando-se a quadruplicação do preço do petróleo -, levou ao aumento do desemprego e da inflação, minando, na década de 1970, a base das coalizões políticas que sustentaram a ação dos Estados Nacionais nas décadas anteriores. A desordem internacional abalou a hegemonia americana no concerto das nações ocidentais. A maneira como os Estados Unidos reagiram ao enfraquecimento de sua hegemonia, no final dos anos 1970, impulsionou a globalização financeira e internacionalização da produção, em meio a importantes avanços técnicos e mudanças na organização da produção de bens e prestação de serviços (Belluzzo, 2004).

A nova ordem internacional, que resultou da reafirmação da hegemonia dos Estados Unidos através da globalização financeira e internacionalização do sistema de produção, reduziu para a maioria dos países o grau de autonomia de ação dos Estados Nacionais. Em particular, a facilidade de deslocamento entre países de fundos aplicados no mercado financeiro instabilizou as taxas de câmbio das moedas dos países, e o comércio entre nações tornou-se desequilibrado e deixou de ser mero complemento do desenvolvimento de sistemas nacionais de produção.

O déficit de comércio dos Estados Unidos impulsionou a internacionalização da produção de bens manufaturados, especialmente o desenvolvimento da produção asiática, inicialmente no Japão e, posteriormente, na Coréia do Sul, Taiwan, na China e em outros países. A Ásia tornou-se o grande fornecedor mundial de produtos manufaturados, contribuindo para a redução de seus preços relativos e ajudando a manter baixa a inflação.

Em outros países, que não os asiáticos e seus fornecedores de matéria prima, o PIB passou a crescer de forma mais lenta e a carga tributária deixou de aumentar. A arrecadação de impostos, então, reduziu o ritmo de ampliação. As despesas do Estado continuaram aumentando em ritmo forte com a ampliação e diversificação das demandas por serviços sociais, através das alterações na composição etária da população, das mudanças na estrutura familiar devido à crescente participação feminina no mercado de trabalho, do aumento do desemprego, da diminuição do nível e ampliação 
da dispersão dos salários e da proliferação de reivindicações vindas de novos movimentos sociais. Os recursos públicos se mostram insuficientes para atender às demandas e cresceram os déficits fiscais. A dívida pública aumentou e as despesas financeiras dos Estados agravaram o déficit do fisco.

Os problemas de financiamento do Estado foram, inicialmente, contornados pelo crescimento dos mercados financeiros com a globalização. Nesse contexto, a inflação diminuiu e o crescimento do PIB mostrou-se muito irregular e com tendência a ser relativamente pouco intenso. A taxa de desemprego continuou elevada e aumentou a fração de ocupações não submetidas à regulação pública do trabalho. Esta, por sua vez, tendeu a descentralizar, voltando-se para questões mais pontuais ao nível da relação de emprego, notando-se uma diferenciação de condições de trabalho e de remuneração dos trabalhadores (Mattos, 2009).

As mudanças na absorção da população ativa e na regulação do trabalho são manifestações de um contexto econômico de maior instabilidade, menor crescimento e ampliação da exposição à concorrência internacional. Nestas condições, os empregadores passaram a reivindicar maior liberdade de ação, o que facilitou a prevalência das teses neoliberais e sua difusão na sociedade e no aparelho do Estado.

A demanda pela liberdade do capital para determinar as condições de contratação, uso e remuneração do trabalho ocorreu em simultâneo a uma desverticalização da produção de bens e serviços, em um quadro de intenso avanço das tecnologias de informação e comunicação. A financeirização da economia obrigou a racionalizar a produção, visando aumentar a rentabilidade do capital aplicado, mantendo somente os ativos estratégicos para o desenvolvimento da empresa e recorrendo mais intensamente a serviços de terceiros (Braga, 2009).

No contexto dessa reorganização econômica e em um quadro político desfavorável aos trabalhadores organizados, ocorreram transformações na regulação do trabalho, reforçando a tendência de flexibilização e de descentralização das condições de contratação, uso e remuneração do trabalho. O capitalismoglobalizado é mais instável eacirra a competição. A empresa reclama por maior liberdade de ação para poder competir, exigindo mais e comprometendo-se menos com o bem estar de seus empregados (Sennett, 1999; Uriarte, 2000; Krein, 2007).

A demanda empresarial por liberdade de ação ocorreu em um contexto de desverticalização da produção. Paradoxalmente, com a globalização financeira e a internacionalização da produção, fusões e aquisições de empresas levaram a uma estruturação mundial da competição, com estratégias que consideram o conjunto de mercados nacionais e não mais cada um deles separadamente. Cada unidade da empresa, entretanto, mantém somente os ativos estratégicos para o seu desempenho e recorre a serviços de terceiros. A busca da flexibilidade e a descentralização dificultaram ações coletivas mais amplas dos trabalhadores e corroeram as bases da regulação pública do trabalho, que se consolidaram no pós-guerra nos países desenvolvidos.

Esses efeitos da reorganização da economia afetaram os empregados permanentes e temporários. Quanto aos permanentes, os empregadores buscaram a flexibilidade funcional, ampliando sua liberdade para determinar os elementos centrais da relação de emprego, tais como a alocação de tarefas, a jornada e a remuneração do trabalho.

A liberdade para alocar a força de trabalho refere-se à determinação, sem amarras, das funções a serem exercidas pelos empregados, exigindo mais polivalência. A tendência é exigir multifuncionalidade dos empregados permanentes, controlando suas atividades por meio de metas e projetos, definidos pela empresa, debilitando a relação entre profissão, tarefas a realizar e remuneração, marcadas no passado por negociação coletiva mais ampla de contratos de trabalho, frequentemente envolvendo a interferência do Estado.

A remuneração do trabalho tendeu a ser mais variável, ficando cada vez mais vinculada ao desempenho do trabalhador, individualmente ou em pequenos grupos na empresa. Programas de participação nos lucros e/ou resultados e remuneração por comissão passaram a ser uma prática corrente 
nos segmentos empresariais mais dinâmicos. Com isso, esvaziou-se a determinação da remuneração por negociação coletiva mais ampla (Freyninnet, 2006).

A regulação do tempo de trabalho também tendeu a ficar mais flexível e adaptada às peculiaridades da empresa, com a modulação da jornada e o descanso não coincidindo, necessariamente, com os fins de semana. A tendência tem sido afastar-se da jornada padrão de 8 horas por dia e 5 dias por semana, que contribuiu para estruturar as políticas públicas e a vida das pessoas em sociedade. Atualmente, prevalece o interesse das empresas, que ajustam a jornada de acordo com suas necessidades. O tempo de trabalho não se separa mais tão claramente do tempo livre das pessoas e os trabalhadores tendem a ficar mais conectados ao trabalho, mesmo fora dele (Dedecca, 1999).

A flexibilidade funcional dos empregados permanentes diz respeito ao núcleo estratégico da empresa. A empresa exige o envolvimento desses empregados na vida da organização, aumentando o desgaste emocional decorrente da pressão por resultados, em uma situação econômica marcada pela instabilidade e acirramento da competição entre empresas. As consequências referem-se tanto à insegurança quanto ao futuro profissional como à proliferação de novas doenças profissionais (Barreto, 2003).

tanto, prevalece a flexibilidade quantitativa, em que a empresa contrata para a prestação de serviços específicos e o contrato dura tanto quanto a necessidade desses serviços. A variedade de situações tem levado a uma ampla diversidade de contratos (a termo, part time, temporário, subcontratados, especial para segmentos da força de trabalho, etc.), aumentando, expressivamente, a heterogeneidade dos assalariados. Essa heterogeneidade é alavancada pelo avanço da subcontratação e crescente uso de terceiros. Freyssinnet (2006) mostrou como essas novas modalidades de contratação proliferam na Europa desde os anos 1980. Assim, a flexibilização quantitativa proporciona graus adicionais de liberdade às empresas, ao facilitarem o ajustamento do "volume do pessoal empregado às flutuações da demanda por seus produtos”. A pressão da concorrência por maior racionalização da produção leva, simultaneamente, a ampliar a flexibilidade funcional dos empregados permanentes e a flexibilidade quantitativa dos empregados temporários. Nos dois casos, aumenta-se a intensificação do trabalho, acentuando a redução do custo da produção (Leal Filho, 1994, p.39). A flexibilidade quantitativa é ainda mais importante em setores de atividade com expressiva sazonalidade. Em todo caso, a atividade das empresas tende a ser mais instável, em decorrência da maior instabilidade da demanda dos produtos e do próprio acirramento da competição entre empresas. O elevado desemprego no quadro político hegemônico desfavorável aos trabalhadores organizados tem diversas implicações: 1) aumenta a pressão das empresas sobre os empregados permanentes para que obtenha melhores resultados; 2) amplia a fração de postos de trabalho correspondentes a empregos temporários; 3) incrementa as diferenças entre os empregados permanentes e temporários. Esta segmentação da classe trabalhadora atinge mais contundentemente os jovens e as mulheres.

A desverticalização da produção e a flexibilização do trabalho foram acompanhadas de outros dois fenômenos com efeitos desfavoráveis à situação dos trabalhadores. De um lado, a ampliação e diversificação das demandas de proteção social não foram acompanhadas pela elevação dos recursos necessários para o atendimento dessas demandas. Uma parte dessas demandas foi canalizada para o sistema privado de proteção social, que se desenvolveu como desdobramento do sistema financeiro (por exemplo, os planos de saúde e fundos de pensão). De outro lado, os sindicatos tiveram dificuldade para encaminhar soluções aos novos problemas trabalhistas, notando-se uma redução do poder de barganha dos sindicatos na maioria dos países (Baglioni, 1994). No pós-guerra, a contratação coletiva do trabalho foi parte de um processo virtuoso de estruturação mais ampla da sociedade, contribuindo para evitar que a heterogeneidade dos empregos gerados se refletisse em amplas diferenças de renda do trabalho e 
estilos de vida dos trabalhadores.

As leis do trabalho, o sistema de proteção social e os sindicatos interagiram positivamente no pós-guerra, ajudando a dar legitimidade à atuação do poder público a favor do desenvolvimento do sistema nacional de produção de bens e serviços. Esta construção política da regulação pública do trabalho fez com que a compra e venda da força de trabalho fosse bastante diferente de uma bolsa de mercadoria. ${ }^{3}$ Oliveira (1994) acrescenta que a regulação pública das relações de trabalho e a elevação do padrão de vida dos assalariados são testemunho de que foi possível encaminhar, positivamente, a luta de classe, compatibilizando o lucro das empresas com a melhora de condições de vida dos trabalhadores.

A desregulação da economia, o acirramento da concorrência e a hegemonia política neoliberal colocaram a agenda de flexibilização do trabalho invertendo a lógica de regulação pública anteriormente prevalecente nos campos econômico, político e trabalhista. De fato, os anos 1980 representaram uma ruptura da regulação social do mercado e das relações de trabalho, procurando restabelecer o livre arbítrio dos empregadores na contratação e na determinação das regras de uso e remuneração da mão-de-obra (Krein, 2007; Dedecca, 1999).

A flexibilização do trabalho não somente colocou em xeque o padrão de relações de trabalho construído no pós-guerra, mas descortinou uma perspectiva de fortalecimento da lógica de mercado na contratação de força de trabalho, que tem se tornado mais parecida a uma bolsa de mercadoria. ${ }^{4}$

\section{INSERÇÃO BRASILEIRA NA GLOBALIZAÇÃO}

A maneira como o Brasil se inseriu na globalização agravou os efeitos desfavoráveis aos

${ }^{3}$ Nas palavras de Esping-Andersen (Hyman, 2005), houve uma "desmercantilização" da força de trabalho.

${ }^{4}$ A visão de que a humanidade estava caminhando para $m$ processo de "desmercadorização" da força de trabalho, na expressão de Esping-Andersen (1990), perdeu sentido, pois tem havido uma fragilização do sistema de proteção social e da contratação coletiva do trabalho (Hyman, 2005). trabalhadores trazidos com as mudanças na organização da produção, promovidas pelo acirramento da competição, levando à internacionalização de importantes cadeias produtivas. As vendas dos produtos finais dessas cadeias internacionalizadas foram as que apresentaram maior ritmo de crescimento no capitalismo contemporâneo, sendo expressão do avanço técnico que permitiu a criação de uma série de novos produtos. A crise da dívida externa e o modo como ela foi enfrentada paralisou a acumulação de capital no país, que ficou defasado diante das grandes mudanças ocorridas na organização de bens, ao longo da década de 1980.

A internacionalização dessas importantes cadeias de produção de bens fez com que o desempenho das economias nacionais, abertas ao comércio e às finanças entre países, dependesse muito da evolução de suas exportações, mesmo quando estas são relativamente pequenas em comparação com o consumo e o investimento. Para usufruir, plenamente, da redução de custo que a internacionalização da produção de bens trouxe, é necessário que o país tenha capacidade para ampliar as suas exportações, de modo a manter sólido o balanço de pagamentos. O contexto pós-abertura, em que a ampliação do consumo e do investimento continuam sendo os principais determinantes de crescimento do PIB, acarreta forte aumento da importação. Além disso, o financiamento internacional da economia implica expressivos déficits na conta renda financeira do balanço de pagamentos (Baltar, 2003).

A entrada na globalização, de modo a favorecer o país, exigia a promoção do desenvolvimento de seu sistema de produção de bens, que tinha ficado defasado na década de 1980, de modo a garantir as possibilidades de ampliação da exportação e de competição com a importação, para que esta última não aumentasse desproporcionalmente, fazendo com que um expressivo crescimento do PIB pudesse ocorrer com um balanço de pagamento sólido. Isto não foi feito. As cadeias internacionais de produção de bens foram estruturadas por grandes empresas transnacionais. A liberalização da importação no Brasil foi indiscriminada e sem 
exigir dessas grandes empresas contrapartida na exportação de produtos manufaturados pelo país. Além disso, a entrada de capital não foi controlada e permitiu-se a valorização da moeda nacional, que dificultou, ainda mais, o desenvolvimento da produção e a capacidade de exportação e de competição com a importação (Santos, 2013).

Na realidade, a entrada na globalização foi precipitada e passiva, porque foi usada para reduzir a inflação, que tinha ficado muito alta com a crise da dívida externa e o modo como ela foi enfrentada. A ilimitada importação barata de produtos manufaturados, coberta pela entrada de capital, ajudou a baixar a inflação, mas agravou os efeitos da falta de ação do poder público para desenvolver o sistema de produção de bens de modo a ampliar a exportação e evitar o aumento desproporcional da importação.

Além disso, o país ficou muito exposto à instabilidade do sistema financeiro internacional. A crise do México, logo depois da implantação do Real, ameaçou a eficácia do plano de estabilização, que dependia da preservação do nível da taxa nominal de câmbio. Para evitar o aumento da taxa de câmbio, com a fuga de capital, o governo aumentou a taxa de juros, prejudicando todos que usavam o crédito em moeda nacional, particularmente o próprio governo, que precisa administrar o refinanciamento da dívida pública. Imobilizado pelo ônus do refinanciamento da dívida pública com altas taxas de juros e sem mais contar com as empresas estatais que foram privatizadas, o Estado brasileiro perdeu grande parte de sua capacidade para coordenar a realização dos investimentos públicos e privados necessários para ampliar a infraestrutura e desenvolver o sistema produtor de bens e para viabilizar o crescimento continuado da economia. O PIB cresceu lentamente, a taxa de investimento pouco aumentou e houve déficit no comércio com outros países, agravando o déficit de conta corrente do balanço de pagamentos, associado, basicamente, às contas de serviços e especialmente dos serviços financeiros.

A produção industrial foi especialmente prejudicada e sua interrelação com a prestação de serviços é fundamental para a geração de empregos de melhor qualificação e renda. A escassa criação desses empregos foi um aspecto importante do agravamento das consequências deletérias gerais das novas formas de organização da produção sobre os trabalhadores. As novas formas de organização da produção dificultaram a construção de empregos de nível de renda intermediário e também fizeram proliferar os empregos de baixo nível de renda. Já os efeitos da maneira como o Brasil entrou na globalização limitaram, também, o surgimento de empregos de alta renda (Quadros, 2008; Baltar, 2003).

As repercussões negativas da inserção do Brasil na globalização sobre os trabalhadores aparecem na condição de atividade da população, na posição das pessoas na ocupação e no tipo dessas ocupações. (Baltar et al, 2010) O crescimento da população economicamente ativa (PEA) continuou muito intenso ao longo da década de 1990. A crescente participação das mulheres adultas na atividade econômica foi a principal responsável pela continuidade desse crescimento da População Economicamente Ativa-PEA, pois o declínio do crescimento demográfico, que vem ocorrendo desde o final da década de 1960, já estava começando a reduzir o contingente de população que alcança a idade ativa. A economia brasileira não gerou oportunidades para ocupar essa crescente população ativa e a taxa de desemprego, no final da década, ficou mais do que o dobro da que prevaleceu no final da década anterior (Pochmann, 2001; Santos, 2013).

O emprego na agropecuária diminuiu ao longo da década de 1990 apesar da expressiva ampliação da produção. A elevação da produtividade e as mudanças na composição da produção por tipo de bens agrícolas explicam essa redução na geração de oportunidades de emprego neste setor de atividade. No conjunto das demais atividades da economia, a ocupação de pessoas aumentou, porém em ritmo bem menor do que no passado, menor, inclusive, do que a década de 1980, quando a crise da dívida paralisou a economia brasileira. A produção dessas atividades não-agrícolas continuou com um medíocre crescimento e os se- 
tores com produtos suscetíveis de comércio com outros países, seja exportação ou importação, perderam a capacidade de geração de emprego e renda, em consequência da globalização. Foi notável a redução do emprego nas grandes empresas, especialmente as da indústria de transformação, construção civil, serviços de utilidade pública, finanças e transporte. Nem toda a redução do emprego nas grandes empresas foi eliminação pura e simples de postos de trabalho. Foi intensa a contratação de serviços de terceiros, que deslocou emprego das grandes empresas para as menores, além de provocar a ampliação do trabalho por conta própria. $\mathrm{O}$ crescimento do emprego continuou expressivo no comércio, em serviços de apoio às empresas e nas atividades sociais do tipo educação, saúde, previdência e assistência social (Baltar, 2003).

O crescimento do emprego em estabelecimento econômico, entretanto, foi muito pequeno, proporcionalmente bem menor do que a ampliação do emprego no serviço doméstico remunerado e no trabalho por conta própria. Além disso, o número de empregadores também aumentou muito com a proliferação de pequenas empresas. Essas mudanças na composição das oportunidades para ocupar a PEA em atividades não-agrícolas foram acompanhadas de forte redução na proporção dos empregos formalizados em conformidade com a legislação trabalhista (Baltar, 2003).

A proliferação de empregos que desrespeitam as leis do trabalho foi uma manifestação peculiar dos anos 1990, evidenciando os efeitos deletérios sobre os trabalhadores da inserção brasileira na globalização e teve a ver com um relaxamento na imposição dessas leis, por um governo que estimulou a iniciativa privada, diante de um quadro de forte estreitamento do mercado de trabalho e com uma PEA que continuou aumentando fortemente (Baltar, 2003).

No sistema brasileiro de relações de trabalho, as leis são muito importantes na definição das regras e normas que estabelecem a relação de emprego e proteção social. A legislação é detalhada, mas o empregador tem muita liberdade para dispensar força de trabalho e, no caso dos empregos onde é elevada a rotatividade, os salários podem ser alterados em função das empresas, sem desrespeitar a legislação. Nesses empregos de alta rotatividade não se acumula tempo de serviço e, portanto, o montante da indenização ao dispensado é relativamente pequena.

Não obstante, a proliferação de pequenos negócios na década de 1990 foi acompanhada de crescente ilegalidade, com ausência do registro da empresa no CNPJ e o não cumprimento das leis do trabalho e da previdência social. A ilegalidade prejudicou os trabalhadores e a arrecadação de impostos e contribuições sociais, mas a reação do poder público não foi impor a lei, mas criar um sistema (SIMPLES) que não somente simplificou, mas também diminuiu os encargos trabalhistas das micro e pequenas empresas (MPE). Os efeitos desse sistema na formalização das MPE e de seus contratos de trabalho aumentou somente depois que o governo de orientação neoliberal teve que reforçar a arrecadação de impostos e contribuições sociais, quando foi obrigado a obter superávit de arrecadação em relação às suas despesas não financeiras, para absolver no orçamento uma parte importante dos juros pagos pela crescente dívida pública.

Ocorreram, nos anos 1990, diversas iniciativas governamentais para promover alterações pontuais nas leis do trabalho e da previdência social. Essas mudanças pontuais proporcionaram ainda mais liberdade de ação aos empregadores na contratação e na definição da jornada e da remuneração. Ampliaram-se as possibilidades do contrato temporário, para além das excepcionalidades previstas na legislação anterior, criou-se o contrato por tempo determinado, antes proibido pela legislação e facilitou-se a contratação como pessoa jurídica (PJ) - que não contrata nenhum empregado , além de facilitar a existência de cooperativas de mão-de-obra. Quanto à jornada de trabalho, permitiu-se o trabalho aos domingos no comércio e instituiu-se o banco de horas para facilitar a modulação da jornada trabalhada, evitando o pagamento de adicional por horas extras. Finalmente, quanto à remuneração, proibiu-se a indexação dos salários e facilitou-se o uso da remuneração variá- 
vel, que não é considerada salário, e, portanto, varia mais facilmente e nela não incidem os encargos trabalhistas. Além dessas mudanças pontais na legislação, tentou-se, sem êxito, alterar o conjunto da legislação trabalhista ao estabelecer que o negociado pelas partes prevalecesse sobre o determinado pela legislação (Krein, 2007).

Num quadro de desemprego e ilegalidade das relações de trabalho e com uma posição do governo relutante na imposição da lei e promovendo alterações visando a dar maior liberdade de ação aos empregadores, observou-se uma tendência da negociação coletiva se descentralizar, predominando acordos por empresas em relação à convenção coletiva. Nesses acordos por empresa, tendeu a prevalecer uma estratégia defensiva de fazer concessões, procurando preservar os empregos existentes ou buscando compensar a dificuldade da negociação salarial na convenção por acordos de participação nos lucros e resultados.

O quadro se modificou e ficou mais desfavorável aos trabalhadores quando, depois da crise da Ásia e da Rússia, o Real se desvalorizou no início de 1999, gerando como consequência o aumento da inflação e a diminuição do poder de compra dos salários. A fuga de capital, provocada pela repercussão no mercado financeiro internacional das crises dos mercados emergentes, paralisou o crescimento do PIB e aumentou o desemprego. Sem crescimento do PIB, com aumento do desemprego e da inflação, os reajustes da grande maioria das categorias profissionais não conseguiram impedir a queda no poder de compra dos salários. O governo, entretanto, aumentou o valor do salário mínimo acima da inflação, de modo que a queda da renda do trabalho, ocorrida entre 1999 e 2004, foi acompanhada pela redução nas diferenças de renda entre os trabalhadores.

O aumento do poder de compra das remunerações mais baixas já vinha ocorrendo desde meados da década de 1990, acompanhando a elevação do valor do salário mínimo e o aumento da idade das pessoas nessas ocupações de baixa remuneração. Apenas em categorias ocupacionais de renda muito baixa como o emprego agrícola sem carteira, o trabalho familiar na prestação de serviços para as indústrias de calçados e confecções no nordeste e empregos domésticos de pessoas muito jovens sem carteira de trabalho não foram beneficiados pelo aumento no valor do salário mínimo, que aconteceu desde 1995 e que se encontrava em um nível muito baixo.

Na década de 1990, entretanto, a posição predominante no debate sobre o trabalho no Brasil deu como dado a continuação do lento crescimento da economia e centrou a discussão na necessidade de redefinir as regras e normas que regem a relação de emprego para dar liberdade de ação às empresas (Krein, Santos e Nunes, 2011). Os aumentos do desemprego e da ilegalidade dos contratos de trabalho evidenciaram a deterioração do mercado de trabalho. Para aqueles que opinam não haver alternativa a uma inserção passiva na globalização, duas posições diferentes sobressaíram quanto à agenda de problemas a ser enfrentada na área trabalhista. Uma dessas posições (Pastore, 1995; Zylbertjan, 1988) destacou a necessidade de acabar com a rigidez provocada pelas regras que regulam a relação de emprego, que, no Brasil, são fortemente marcadas por um arcabouço legal muito detalhado, que estabelece direitos e obrigações, deixando pouco espaço de adaptação em negociação direta das partes da relação de emprego. Ou seja, conforme essa posição, as leis teriam que ser modificadas para permitir maior flexibilidade na contratação, uso e remuneração do trabalho. Empresas e empregados teriam mais liberdade para se adaptar à realidade da economia globalizada e de produção internacionalizada. A empresa pagaria estritamente pelas horas trabalhadas e não teria tantos encargos associados à contratação de mão-de-obra e o salário pela hora trabalhada seria negociado diretamente pelas partes em função das circunstâncias enfrentadas pela empresa, levando em conta as dificuldades de recrutamento e de adaptação dos trabalhadores aos postos de trabalho. Nessa perspectiva, portanto, a agenda é a de desconstrução das leis do trabalho, deixando para as partes a negociação dos contratos, sem previsão dos mecanismos que viabilizassem uma 
contratação coletiva, mesmo que estritamente ao nível do local de trabalho.

A outra posição (Camargo; Amadeo, 1996), que também valoriza o efeito da abertura da economia, no sentido de liberar a iniciativa privada e intensificar a competição, achando inconveniente uma interferência pública para melhorar o desempenho da economia e geração de emprego e renda, destaca, na raiz do aumento do desemprego e da ilegalidade dos contratos de trabalho, problemas de adaptação das empresas ao acirramento da competição, que não estaria induzindo comportamentos adequados de patrões e empregados na direção de um maior compromisso no local de trabalho, que favoreceriam o aumento da produtividade e da competitividade. Esta posição tem uma opinião diferente sobre o arcabouço legal determinante das normas de contratação, uso e remuneração do trabalho. A lei não impediria a liberdade de ação da empresa, mas aspectos importantes do arcabouço legal tendem a induzir comportamentos inadequados de trabalhadores e empregadores, prejudicando aquele compromisso favorável à produtividade e à competitividade. Assim, por exemplo, FGTS e seguro-desemprego generoso e com base em impostos estimulam comportamentos oportunistas de trabalhadores e empregadores, contribuindo para a existência de um regime de trabalho em que se evita o ônus de uma seleção mais criteriosa na contratação à custa da duração dos vínculos de emprego, em prejuízo da adaptação dos trabalhadores às características dos postos de trabalho e ao desenvolvimento de compromissos favoráveis à produtividade. A lei pressupõe que os contratos de trabalho têm duração indefinida e impõe penalidades e indenizações pela ruptura dos contratos, mas a reclamação dos direitos na Justiça do Trabalho pressupõe o desligamento dos empregados e a morosidade da Justiça termina estimulando acordos entre as partes que negociam o montante das indenizações. O próprio sindicato, mantido com recursos decorrentes de impostos e contribuições obrigatórias, não é induzido a buscar uma verdadeira representação dos empregados, cujo emprego e remuneração pressu- põem a competitividade do empregador.

As duas posições mencionadas destacam as virtudes da abertura, no sentido de promover a iniciativa privada e a competição, e, se levaram a resultados negativos de emprego e renda, foi porque o ambiente legal e institucional não se mostrou adequado para uma resposta positiva de empresas e empregados aos estímulos do acirramento da competição. O debate, então, deveria se centrar na necessidade de modificar o arcabouço legal e institucional. Uma terceira posição (Cardoso, 1999), menosprezada ao longo da década de 1990, destacou a própria maneira como se fez a abertura da economia na globalização financeira e internacionalização da produção e não os condicionantes legais institucionais do comportamento de empregadores e empregados na contratação, uso e remuneração do trabalho. As mudanças na organização da produção, com lento crescimento do PIB, aumentaram o desemprego e a ilegalidade dos contratos de trabalho e as alterações pontuais no arcabouço legal institucional apenas agravaram a precariedade do trabalho (Krein, Santos e Nunes, 2011).

\section{A REDEFINIÇÃO DOS TERMOS DO DEBATE SOBRE TRABALHO NO BRASIL COM A RETOMADA DO CRESCIMENTO ECONÔMICO EM 2004}

A maneira como o Brasil fez a abertura deixou a economia extremamente dependente da situação internacional em termos de finanças e comércio. Assim, as crises da Ásia e da Rússia em 1997 e 1998 provocaram fuga de capital, deteriorando ainda mais a situação do mercado de trabalho como mostra a elevação da taxa de desemprego e a queda expressiva do poder de compra da renda do trabalho entre 1998 e 2003. O desemprego aumentou com a queda na taxa de crescimento do PIB. A combinação de aumentos do desemprego e da inflação provocou uma diminuição substantiva do poder de compra da renda do trabalho (Baltar et al, 2008). 
A situação se reverteu completamente com os efeitos sobre a economia brasileira do crescimento da demanda e aumento dos preços internacionais das commodities, a partir de 2003. O crescimento do PIB ficou mais forte, a inflação diminuiu, cresceu muito o emprego formal e recuperou-se o poder de compra da renda do trabalho. Fortes aumentos do valor do salário mínimo e reajustes das categorias profissionais maiores do que a inflação fizeram com que a elevação do poder de compra da renda do trabalho acontecesse com diminuição das diferenças entre trabalhadores. Foi a primeira vez, desde 1960, que um aumento substantivo da renda do trabalho ocorreu com diminuição do índice de GINI. O crescimento do PIB, a diminuição do desemprego, o aumento do poder de compra da renda do trabalho e a queda da inflação, e tudo isso ocorrendo com ampliação das reservas internacionais em relação à dívida externa do país, criaram um clima na economia brasileira em que as famílias passaram a se endividar para ampliar o consumo, apesar das elevadas taxas de juros, e os bancos atenderam a essa maior demanda de crédito. $O$ intenso crescimento do consumo foi fundamental para o bom desempenho da economia brasileira e a melhora dos indicadores do mercado de trabalho desde 2004 (Baltar et al, 2008).

Esse quadro de crescimento da economia e

\section{de melhora dos indicadores do mercado de traba-} lho redefiniu os temas da agenda de debates na área trabalhista. A melhora nas condições de funcionamento da economia brasileira, permitida pela expansão das exportações, viabilizou a simultaneidade de intensos aumentos de emprego e de salários com redução da inflação, contrariando opiniões pessimistas que costumam relacionar, inversamente, os níveis de emprego e salário, e, diretamente, o aumento dos salários e inflação. Essa simultaneidade de indicadores positivos da produção, do emprego, do salário e dos preços ocorreu sem qualquer alteração mais substantiva do arcabouço legal institucional que determina as condições de uso, contratação e remuneração do trabalho, mostrando a precipitação das conclusões das duas vertentes predominantes do debate da área trabalhista nos anos 1990, que minimizaram o papel de tentar influir nas condições de funcionamento da economia, destacando, exclusivamente, as alterações no arcabouço legal institucional da regulação pública do trabalho, adequando-o, enviezadamente, às mudanças na organização da produção, de modo a facilitar a flexibilização do trabalho e a liberdade de ação das empresas.

A experiência dos anos 1990 e 2000 mostrou que os temas relevantes da discussão sobre regulação do trabalho são muito afetados pela maneira como evoluíram a produção, os preços, o emprego e os salários. As transformações na organização da produção, com sua internacionalização nos anos 1990, colocam problemas novos para a regulação pública do trabalho ao apontar para uma ampliação, como mencionado, da flexibilidade funcional e quantitativa. Nas condições políticas e de mercado de trabalho em que essas transformações ocorreram, na década 1990, a flexibilização foi sinônimo de precarização do trabalho, resultando em simples ampliação da liberdade de ação da empresa em um contexto desfavorável aos trabalhadores. No entanto, em uma situação política e de mercado de trabalho mais favorável aos trabalhadores, como nos anos 2000, os problemas novos, decorrentes das mudanças na organização da produção, poderão ser enfrentados pela regulação pública (leis e contratos coletivos), de um modo que não resulte em precarização do trabalho e, ao contrário, contribua para uma melhor estruturação do trabalho assalariado diante das novas tendências na organização da produção (Krein, Santos e Nunes, 2011).

Uma das principais alterações na organização da produção foi o crescente uso de terceiros (terceirização). A terceirização coloca sérios problemas e tem sido uma fonte de precarização do trabalho. Em uma situação econômica mais favorável, é possível realizar um debate mais relevante acerca da terceirização. Esse debate tem, pelo menos, os seguintes aspectos: que atividades podem ser terceirizadas; proibição da atividade que seja simplesmente a alocação de mão-de-obra por parte de outra empresa; a representação dos terceirizados 
seja a mesma que a dos empregados da empresa e, portanto, que ambos sejam protegidos pelo mesmo instrumento normativo;e responsabilidade solidária da contratante em relação à contratada, caso não sejam respeitados os instrumentos normativos. A regulamentação da terceirização deveria garantir essas condições no uso de terceiros para evitar que conduza à precarização do trabalho.

As mudanças na organização foram acompanhadas pela proliferação de novas formas de contratos de trabalho. Algumas dessas formas de contratação não aparecem como relação de emprego, ou seja, a relação de emprego fica disfarçada: o uso abusivo de estagiários substituindo profissionais, as falsas cooperativas de trabalho, empregados contratados como autônomos ou pessoa jurídica. Essas modalidades de contratação buscam burlar a legislação vigente para diminuir despesas, constituindo fraudes que devem ser duramente reprimidas. No caso das contratações em que aparece o vínculo de emprego, destacam-se os diferentes tipos de contratos temporários (setor público e privado), por obra certa, safra, por prazo determinado. O que chama atenção é a ampliação da frequência e continuidade destes tipos de contratos. No caso das fraudes, é preciso fortalecer os instrumentos de fiscalização e as punições. No caso das contratações temporárias, é preciso melhorar sua regulamentação para evitar os abusos de contratos temporários em relação de emprego que poderia ser mais duradora.

As mudanças na organização da produção têm levado a uma diminuição do corpo permanente dos empregados da empresa, intensificando a flexibilidade funcional dos permanentes e a flexibilidade quantitativa dos demais. Para muitos empregados, o próprio local de trabalho fica indefinido como no caso do teletrabalho. Além da proliferação dos contratos atípicos, observa-se a continuidade de altas taxas de rotatividade dos contratados por tempo indefinido. A rotatividade é agravada pela inexistência ou pela inoperância de mecanismos contra a dispensa imotivada e a debilidade da organização dos trabalhadores no local de trabalho. O fortalecimento desses mecanismos e organizações é fundamental para a redução da rotatividade, que prejudica uma melhor adaptação da força de trabalho às peculiaridades dos distintos postos de trabalho.

A internacionalização da produção coloca a necessidade de uma ampla revisão do sistema de impostos e contribuições para a seguridade social. Nesse contexto, coloca-se a questão da desoneração da folha de salários, de modo a não penalizar a produção, que gera mais emprego sem prejudicar a arrecadação de recursos públicos. A discussão refere-se, explicitamente, à forma de cobrar os impostos e não à magnitude da carga tributária, hoje em 35\% do PIB, sendo fundamental para a consolidação das políticas sociais definidas na Constituição Federal de 1988.

As mudanças na organização da produção têm implicado em aumentos tão expressivos de produtividade que se coloca a discussão de como aproveitar esse avanço em termos de favorecer o bem estar da população. Nesta perspectiva, podese fazer uma contraposição entre ampliar o consumo privado de bens e serviços, ampliar os serviços públicos ou reduzir a jornada de trabalho em sentido amplo, que envolve, não apenas a jornada diária e semanal, mas também as férias e feriados, a aposentadoria, o retardamento da entrada dos jovens no mercado de trabalho. A opção na forma de como aproveitar os ganhos de produtividade tem diferentes implicações na regulação do trabalho. Por exemplo, a ampliação dos serviços públicos coletivos exigirá maior carga tributária. A opção de reduzir jornada e produção de bens e serviços tem implicações no sentido de diminuir a utilização de recursos naturais com benefícios ecológicos. As mudanças na organização da produção, com tendência de flexibilização e descentralização, têm implicado a intensificação do trabalho com efeitos deletérios sobre a saúde dos trabalhadores. O debate deste assunto é extremamente importante para informar a regulação pública do trabalho e ampliar as políticas de proteção social.

A tendência de flexibilidade funcional tem sido acompanhada do aumento do peso da remuneração variável e constituído formas diferencia- 
das de organização da jornada de trabalho (modulação, turnos, escalas). Estas duas tendências têm provocado uma enorme diversidade de situações entre os trabalhadores, problematizando a própria existência da regulação pública do trabalho, que terá que contemplar a remuneração variável e a organização da jornada para delimitar a variedade de situações dos trabalhadores que dificulta a regulação pública do trabalho.

As atuais tendências de flexibilização e de descentralização da produção colocam desafios para a regulação pública do trabalho, que terá que aperfeiçoar as normas, desde o marco legal até os apoios para fortalecer as instituições (públicas/estatais e entidades classistas) que produzem e fazem cumprir as normas do trabalho. Neste particular, hoje é mais necessário do que nunca o fortalecimento da organização dos trabalhadores no local de trabalho.

Deste modo, uma evolução mais favorável aos trabalhadores da produção, emprego, salários e preços permitiu colocar, de modo mais adequado, as novas questões que devem ser enfrentadas pela regulação pública do trabalho, levantadas pelas tendências de mudanças na organização da produção. Essa evolução da produção, emprego, salário e preços ocorreu sem mudanças significativas na forma de inserção do país na economia mundial, mas esta última se comportou de modo mais favorável ao desempenho econômico do país. Esta realidade vem se modificando a partir da crise mundial.

A melhora nos indicadores do mercado de trabalho no Brasil vem ocorrendo desde 2004 e não foi interrompida pela crise mundial. Com reserva internacional e com pouca dívida indexada ao dólar, a reação do governo ao impacto inicial da crise foi eficaz. A desvalorização do Real, em vez de piorar, melhorou as contas públicas ao aumentar o valor em reais das reservas internacionais. Dispondo de recursos, o governo pode agir para amortecer o impacto da crise. Reduziu, temporariamente, impostos indiretos sobre produtos, manteve a programação dos investimentos públicos, continuou aumentando o salário mínimo e fortaleceu os bancos públicos para que pudessem com- pensar a retração dos privados no atendimento da demanda de crédito.

O PIB caiu somente 0,3\% em 2009 e aumentou 7,5\% em 2010. A intensidade da recuperação fez o novo governo, em 2011, atuar no sentido de conter a atividade da economia. Isto prejudicou a continuação dos investimentos públicos e a sustentação do crescimento do consumo. Diante desse quadro e dada a incerteza da situação internacional, o investimento privado, que tinha se recuperado fortemente em 2010, perdeu muito do seu ímpeto. O crescimento do PIB foi de somente 2,7\% em 2011, evidenciando os efeitos da estratégia de conter o ritmo da recuperação neste ano. $\mathrm{O}$ governo, então, procurou reanimar a economia, mas o resultado foi muito menor do que o observado em 2010, e o crescimento do PIB foi somente $0.9 \%$ em 2012. Os estímulos determinados pelo governo contiveram a desaceleração do consumo, mas não impediram a queda do investimento que, em 2012, foi menor do que 2011.

Existe um relativo consenso de que, atualmente, um crescimento mais forte do PIB requer a ampliação da taxa de investimento. O país não pode contar mais com uma evolução favorável dos termos de troca do comércio internacional que favoreceu o desempenho da economia brasileira em 2007 e 2008. Atualmente, é preciso aumentar a produtividade da economia para continuar melhorando a condição socioeconômica da população e isto requer investimento em infraestrutura e no fortalecimento da competitividade da produção manufatureira existente no país.

A crise mundial prejudicou a atividade econômica nos países desenvolvidos e acirrou a competição internacional pela demanda de produtos manufaturados. A sustentação do crescimento do consumo no Brasil tem provocado um forte aumento da importação de produtos manufaturados em detrimento da produção doméstica, que chegou a diminuir em 2012. O déficit de comércio exterior com produtos manufaturados que tinha fica muito grande em 2008, multiplicou por 2,5 em 2011 e se repetiu em 2012.

O comércio internacional de produtos ma- 
nufaturados é, em grande medida, no interior das próprias empresas transnacionais. O Brasil ficou fora das cadeias de produção internacionalizadas e, mesmo onde não é grande essa internacionalização, as empresas multinacionais têm optado por importar partes e componentes da matriz ou de outras filiais onde apresenta grande capacidade ociosa, em vez de investir na ampliação da capacidade de produção instalada no Brasil. Esse movimento comercial reflete a estratégia das matrizes para enfrentar os efeitos da crise mundial e se mostrou pouco afetado pelo aumento da taxa de câmbio no Brasil.É preciso reverter esse movimento, negociando com as empresas investimentos no Brasil, como pré-condição para o acesso ao crescente mercado doméstico (Sarti; Hiratuka, 2011).

A desaceleração do PIB em 2011 e 2012 mostrou as dificuldades encontradas para aumentar a taxa de investimento no quadro de crise mundial. A partir de então, existe um debate na sociedade brasileira sobre o papel do Estado para aumentar a taxa de investimento. Por um lado, o governo tem tomado uma série de medidas para estimular o investimento, tais como: a redução da taxa básica de juros, a elevação da taxa de câmbio, a redução do preço da eletricidade, a criação de empresas estatais para coordenar os investimentos privados em infraestrutura realizados por meio de concessões, entre outros. Por outro lado, é crescente a crítica a essas ações por parte dos setores conservadores e neoliberais, estabelecendo, em articulação com a grande mídia, um contraponto na perspectiva de reduzir o papel do estado e ampliar a liberdade de ação da iniciativa privada. É um embate que começa com o PAC e o fortalecimento dos bancos públicos, a partir de 2006. Essa é uma questão vital para a retomada do desenvolvimento da economia brasileira.

A política econômica, entretanto, tem conseguido preservar a melhora nos indicadores do mercado de trabalho, amortecendo a desaceleração que tem ocorrido no crescimento do consumo. Este cresceu em média 5,4\% ao ano em 2007 e 2008, manteve a média de 5,5\% ao ano em 2009 e 2010 e se ampliou em média 3,2\% ao ano em 2011 e 2012.
A comparação dos períodos 2003/2008 e 2008/2012 mostra que o crescimento do PIB desacelerou da média de $4,8 \%$ ao ano para $2,6 \%$. A desaceleração do crescimento da população ocupada, calculada pela PME/IBGE, foi menor ao passar da média anual 2,7 para 2.1\%. O PIB por pessoa ocupada aumentou mais em 2003/2008 do que em 2008/2012, mas o poder de compra da renda média do trabalho continuou aumentando, apesar do aumento da inflação. O aumento nominal da renda média do trabalho foi maior do que a inflação. Contribuiu para isto tanto a ampliação dos serviços que explicam o aumento do emprego, apesar da desaceleração do PIB, quanto o enorme déficit de comércio externo de produtos manufaturados.

O déficit de comércio externo de produtos manufaturados foi coberto pelo superávit de commodities, mas ocorreu expressivo déficit de conta corrente de balança de pagamento por causa dos serviços, especialmente a remessa de lucros e dividendos. O déficit de conta corrente foi coberto por entrada de capital, especialmente investimento direto estrangeiro. Porém a continuidade desta situação exigiria manter forte aumento das exportações, que até agora tem ocorrido com os altos preços das commodities. Estes, provavelmente, não reverterão no futuro próximo, mas não continuarão aumentando com tanto vigor como no passado recente.

Portanto, a continuação da melhora nos indicadores no mercado de trabalho pressupõe o aumento da taxa de investimento, que aceleraria o crescimento do PIB e aumentaria mais fortemente o PIB por pessoa ocupada. O governo tem atuado nesta direção, como mencionado acima. É, entretanto, fundamental para o aumento da taxa de investimento a ampliação dos investimentos públicos e a negociação com as empresas multinacionais para que ampliem o investimento no Brasil e moderem a importação de partes e componentes de seus produtos. O crescimento mais vigoroso do PIB viabilizaria o crescimento mais robusto do consumo, ajudando a preservar o crescimento do número de pessoas ocupadas e mantendo a taxa de desemprego relativamente baixa.

A PME indica que o número de desempre- 
gados, que tinha atingindo o equivalente a 19,2\% dos empregados assalariados em 2003, diminuiu para 11,3\% em 2008 e alcançou 7,5\% em 2012. A taxa da rotatividade do emprego assalariado formal é $4,5 \%$ ao mês. Para aumentar em $2 \%$ o emprego em um ano, é preciso contratações mensais da ordem de $4,7 \%$ do total do emprego assalariado. A existência de um número de desempregado equivalente a $7,5 \%$ do emprego assalariado não parece indicar que a economia esteja operando em pleno emprego.

As empresas que estão aumentando o emprego não reclamam da dificuldade de encontrar trabalhadores disponíveis, mas sim, da inadequação dos trabalhadores às características dos postos de trabalho. Esse tipo de problema não tem tanto a ver com a baixa taxa de desemprego quanto reflete a existência de altas taxas de rotatividade no emprego.

As empresas alegam que alta rotatividade reflete a inadequação dos trabalhadores disponíveis para os postos de trabalho. Porém, esse problema é reflexo da desestruturação do mercado de trabalho, devido, principalmente, à excessiva liberdade de ação dos empregadores que, além de pagar mal frente à sofisticação já alcançada do aparelho produtivo existente no país, dispensa o empregado logo que já não precisa dele. Não tem que justificar a ninguém a causa da dispensa, bastando indenizar o dispensado, sendo que essa indenização é pequena para quem não tem como acumular tempo de serviço.

A rotatividade no emprego aumenta quando melhora o mercado de trabalho por iniciativa dos empregadores e dos próprios empregados. Isto coloca problemas no recrutamento e esses problemas ficam ainda mais graves com as tendências demográficas que vêm alterando, substancialmente, a composição da população brasileira por idade.

No passado, enquanto a industrialização provocava forte crescimento do PIB e intensa expansão do mercado de trabalho, a elevada rotatividade no emprego renovava, constantemente, a força de trabalho assalariada. A parcela de empregados jovens continuava muito grande, realimentada por rápido crescimento da popula- ção, que, com baixa escolaridade, entrava precocemente no mercado de trabalho. Os jovens transitavam por empregos sem vínculo estável e, com a idade, encontravam crescentes dificuldades de recolocação, tendendo a ser expulsos do mercado de trabalho. Isto provocava uma alta fração da PEA adulta em trabalhos por conta própria. $\mathrm{O}$ adulto expulso do mercado de trabalho tinha que inventar um negócio próprio tivesse ou não condição para fazê-lo. Isto provocava uma dispersão de renda do trabalho por conta própria que era ainda maior do que a dos salários dos empregados.

A população jovem está diminuindo e o aumento de sua escolaridade tem levado ao adiamento da entrada no mercado de trabalho. Isto tem mudado rapidamente a composição da PEA por grupo de idade. Uma força de trabalho assalariada mais adulta é menos maleável, tendendo a aumentar as reclamações dos empregadores quando há inadaptação dos trabalhadores disponíveis às características dos seus postos de trabalho.

O que deve ser corrigido é a alta rotatividade no emprego, estruturando o trabalho assalariado, com as pessoas se vinculando a determinados postos de trabalho. O momento oportuno para essa correção de rumo é, justamente, quando a economia está crescendo e ampliando o mercado de trabalho. Não tem sentido a proposta de conter a atividade da economia na espera que melhore a oferta de trabalho. Ao contrário, uma economia crescendo cria as condições necessárias para construir o seu mercado de trabalho.

Não nos parece adequado aumentar o montante da indenização visando reduzir a rotatividade. Émais eficaz fortalecer os instrumentos institucionais de controle da dispensa imotivada. A exigência de ter que justificar a dispensa perante um inspetor do trabalho ou um sindicato significa uma rigidez, mas, nesse caso, é, justamente, a extrema flexibilidade que está prejudicando o funcionamento do mercado de trabalho.

Quando se trata da inadaptação da força de trabalho aos postos de trabalho, muitos remetem o problema ao baixo nível de qualificação profissional. Alguns chegam a pensar que esse baixo nível 
de qualificação profissional tem a ver com baixo grau de escolaridade da força de trabalho. Esse tipo de questionamento, entretanto, diz respeito a uma pequena parcela da força de trabalho assalariada, que é altamente especializada e relativamente bem remunerada. A inadequação dos empregados aos postos de trabalho é uma questão muito mais ampla e atinge, também, postos de trabalho que não têm tantas exigências de qualificação profissional.

Para essa grande maioria, o problema principal é a alta rotatividade, que impede a fixação dos trabalhadores no entorno de determinados postos de trabalho, que ajudaria os assalariados a se adaptarem às características dos empregos existentes. Caso isso acontecesse, as empresas passariam a contar com empregados profissionalmente melhor capacitados e os trabalhadores teriam melhores condições para se organizar e construir posições de barganha, na perspectiva de reivindicar, coletivamente, uma melhor participação nos aumentos de produtividade, reduzindo as enormes taxas de exploração que ocorrem no Brasil.

A continuidade da melhora do mercado de trabalho pressupõe aumentar a taxa de investimento, o crescimento do PIB e o aumento da produtividade do trabalho na indústria e nos serviços funcionalmente relacionados ao desenvolvimento da indústria. Isto, provavelmente, aumentará a fração da força de trabalho que é mais especializada e melhor remunerada. Nesse caso, será fundamental estruturar o conjunto da força de trabalho assalariado, reforçando os mecanismos institucionais que reduzem a rotatividade e promovem aumentos mais generalizados da renda do trabalho (salário mínimo e reajustes das categorias profissionais), para que o aumento do poder de compra da renda do trabalho prossiga com redução das diferenças entre os trabalhadores.

\section{CONSIDERAÇÕES FINAIS}

A experiência dos países desenvolvidos mostrou a importância da regulação pública do trabalho para a estruturação da sociedade e o bem estar coletivo da população. Essa experiência ressaltou. não somente os efeitos positivos da construção da regulação pública do trabalho, mas também os efeitos deletérios da perda de eficácia desta regulação. De um lado, a regulação pública do trabalho, junto com a proteção social, estruturou a compra e venda da força de trabalho de modo a contribuir para estabilizar e reforçar a tendência de crescimento da produção e do emprego. De outro lado, mudanças contemporâneas no capitalismo desafiaram a regulação pública do trabalho e a ação coletiva dos trabalhadores. A perda de eficácia desta regulação ajudou a reforçar a instabilidade e a redução da tendência de crescimento da produção e do emprego, implicando desemprego e aumento das diferenças socioeconômicas entre os trabalhadores.

Aglobalizaçãofinanceiraeainternacionalização da produção de bens e serviços estão no cerne das transformações contemporâneas no capitalismo. A organização da produção se modificou com tendência à descentralização e flexibilização do trabalho. O quadro político gestado pela predominância do neoliberalismo, não somente promoveu essas mudanças, mas também ajudou a ampliar o impacto desfavorável na regulação pública do trabalho, que, em vez de moldar as mudanças de maneira a evitar a precarização das relações de emprego, reforçou esses efeitos, apoiando a liberdade de ação dos empregadores para se adaptarem ao ambiente de acirramento da competição.

A maneira como o Brasil entrou na globalização financeira e internacionalização da produção reforçou os efeitos deletérios sobre a regulação pública do trabalho. O oportunismo de aproveitar a globalização para diminuir, rapidamente, a inflação prejudicou o fortalecimento da economia na perspectiva de aumentar a exportação e a competitividade da produção doméstica diante da importação. O Brasil, que não tinha participado da internacionalização das cadeias de produção, continuou fora delas e com um sistema de produção voltado, fundamentalmente, para o mercado doméstico.

O desempenho da economia brasileira, em termos de crescimento do PIB e inflação, ficou 
muito dependente da situação do comércio e das finanças internacionais. Na década de 1990, o comércio e as finanças internacionais foram desfavoráveis ao desempenho da economia brasileira e aumentou muito o desemprego e a ilegalidade dos contratos de trabalho.

No debate sobre trabalho duas posições básicas se confrontaram: (1) a que valoriza os efeitos da abertura da economia, aumentando a competição entre empresas e advogando por uma mínima interferência estatal e; (2) a que destaca a importância desta última interferência para fortalecer a economia nacional, o que é particularmente importante diante da abertura que expõe essa economia à competição internacional. A primeira posição avalia o marco regulatório em função dos estímulos ao comportamento de empregadores e empregados, contribuindo, de modo consistente, para o uso eficiente dos recursos diante do aumento da competição provocado pela abertura. Deste ponto de vista, a flexibilidade do trabalho seria parte de uma acomodação da maneira de realizar os negócios sob intensa competição internacional, permitindo o aproveitamento das oportunidades existentes. A segunda posição, ao contrário, destaca a interferência do poder público para garantir a regulação pública do trabalho, na perspectiva de que as oportunidades de negócios sejam mais amplas e aproveitadas de um modo que ajude a construir relações de trabalho que contribuam para uma estruturação melhor da sociedade, legitimando a atuação do Estado.

O comércio e a finança internacional favoreceram o desempenho da economia brasileira na primeira década dos anos 2000. Sem grande interferência estatal para fortalecer a economia nacional, foi possível um crescimento mais forte do PIB, gerando mais empregos formais, a inflação diminuiu e a renda do trabalho aumentou. Um quadro mais favorável aos trabalhadores reforçou a melhora nos indicadores do mercado de trabalho e intensificou o crescimento do PIB. Destacaram-se o aumento do valor do salário mínimo, os reajustes das categorias profissionais acima da inflação e a implementação de um sistema de proteção social em conformidade com os ditames da Constituição Federal de 1988.

A melhora dos termos de troca do comércio exterior do país, favorecida pelos preços internacionais das commodities, desempenhou um papel análogo ao correspondente aumento da produtividade, sem que tivesse havido um aumento mais substantivo da taxa de investimento. No auge do crescimento, em 2007 e 2008, a produção industrial chegou a aumentar em ritmo significativo, apesar da explosão de produtos manufaturados. A ampliação do consumo e do investimento deu oportunidade para desenvolver a produção mais competitiva com importações. A crise mundial, que atingiu o Brasil no final de 2008, mostrou que o quadro internacional deixou de ser tão favorável ao desempenho da economia brasileira. É, então, necessário fortalecer a economia, ampliando a taxa de investimento para que o aumento da produtividade permita a continuação da melhora dos indicadores do mercado de trabalho e o PIB volte a crescer mais forte em benefício do conjunto da população brasileira. Isto, entretanto, pressupõe o aperfeiçoamento da regulação pública do trabalho de modo a impedir que as mudanças na organização da produção levem a uma precarização do trabalho. A retomada do crescimento, com maior taxa de investimento e o maior aumento da produtividade, deve aumentar a proporção de ocupações mais especializadas e melhor remuneradas. Neste contexto, é fundamental melhorar a regulação pública para reduzir a rotatividade, elevar o salário mínimo e ter reajustes das categorias profissionais compatíveis com a maior produtividade, evitando que a ampliação da fração de ocupações mais especializadas resulte em aumento da dispersão dos salários.

O momento que o país atravessa é crucial na definição das possibilidades de desenvolvimento futuro da economia e da sociedade. As posições no debate se localizam entre dois polos: 1) a defesa de uma estruturação do mercado de trabalho com implicações na qualidade das relações sociais; 2) a afirmação dos negócios, que destaca a necessidade de maior flexibilização na contratação, 
no uso e na remuneração do trabalho. O embate dessas posições na sociedade se reflete no conteúdo e na forma das políticas públicas do trabalho e no modelo de desenvolvimento do país. Nesta avaliação mais ampla, não é possível desvincular a discussão da regulação ou estruturação do mercado de trabalho das questões centrais que definem qual será o modelo de desenvolvimento do país.

Recebido para publicação em 06 de abril de 2013 Aceito em 11 de junho de 2013

\section{REFERÊNCIAS}

ABRAMO, L. Mercado de trabajo, flexibilización y nuevas formas de regulación. Cadernos do Cesit. Campinas, n. 29, jul. 2000.

AMADEO, E.; CAMARGO, J. M. Instituições e o mercado de trabalho no Brasil. In: CAMARGO, José Márcio (Org.). Flexibilização do mercado de trabalho no Brasil. Rio de Janeiro: Fundação Getúlio Vargas, p. 47-94, 1996.

ARAÚJO, A. M.; OLIVEIRA, R. V., El sindicalismo en la era de Lula: entre paradojas y nuevas perspectivas. Revista Latinoamericana de Estudios del Trabajo. México, v. 5, n. 2, p. 83-112. 2011

BAGLIONI, G. As relações industriais na Europa nos anos 80. In: Oliveira, C. A. et al (Org.). O mundo do trabalho: crise e mudanças no final do século. São Paulo: Scritta, p.49-106, 1994 .

BALTAR et al. Moving towards decent work. Labour in the Lula government: reflections on recent Brazilian experience. In: Global Labour University Working Papers, n. 9 , p. $38,2010$.

. Evolução do mercado de trabalho e significado da recuperação do emprego formal nos anos recentes. In. DEDECCA, C.S.; PRONI, M.W. Políticas públicas e trabaIho. Campinas: IE/UNICAMP, p.29-52, 2008.

O mercado de trabalho no Brasil dos anos 90. Tese (Livre-Docência) - Instituto de Economia, Universidade Estadual de Campinas, Campinas. 2003.

BARBOSA, N.; PEREIRA DE SOUZA, J. A. A inflexão de Governo Lula. Política econômica, crescimento e distribuição de renda. In: SADER, E.; GARCIA, M. A. (Orgs.) Brasil entre o passado e o futuro. São Paulo: Boitempo Editorial, p. 57-110, 2010.

BARRETO, M. Violência, saúde e trabalho: uma jornada de humilhações. São Paulo: Editora Educ, 2003, 233p.

BELLUZZO, L. G. de M. Ensaios sobre o capitalismo no século XX. São Paulo: Editora Unesp, 2004, 239p.

BRAGA, J. C. S. Crise sistêmica da financeirização e a incerteza das mudanças. Estudos Avançados, v. 23, n 65, p. 89-102, 2009.

CARDOSO JR, J. C. As fontes de recuperação do emprego formal no Brasil e as condições para sua sustentabilidade temporal. X ENCONTRO NACIONAL DA ASSOCIAÇÃO BRASILEIRA DE ESTUDOS DO TRABALHO - ABET. Salvador, 2007.
CARDOSO, A. M. Sindicatos, trabalhadores e a coqueluche neoliberal. Rio de Janeiro: Fundação Getúlio Vargas Editora, 1999, 188p.

A década neoliberal e a crise dos sindicatos no

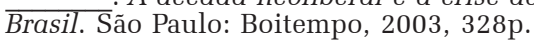

DEDECCA, C. Racionalização econômica e trabalho no capitalismo avançado. Campinas: Instituto de Economia/ UNICAMP, 1999 (Coleção Teses).

DIEESE. O Balanço das negociações salariais em 2010. Estudos e Pesquisas. São Paulo: DIEESE, n. 55, 2011.

Rotatividade e flexibilidade no mercado de trabalho. São Paulo: DIEESE, 2011a.

FILGUEIRAS, V. Estado direito do trabalho no Brasil: regulação do emprego entre 1988 e 2008, 2012. $473 \mathrm{f}$. Tese (Doutorado em Sociologia). Universidade Federal da Bahia, Salvador, 2012.

GIMENEZ, D. M. A política de emprego no século XX e o significado da ruptura neoliberal. São Paulo: Annablume, 2003.

HYMAN, R. Europerização ou erosão das relações laborais? In: ESTANQUE, E. et al. Mudanças no trabalho e ação sindical: Brasil e Portugal no contexto da transnacionalização. São Paulo: Editora Cortez, 2005.

KREIN, D. As tendências recentes nas relações de emprego no Brasil: 1990-2005. (Tese) Universidade Estadual de Campinas, Campinas, 2007.

; SANTOS, A. L.; NUNES, B. 2011. Balanço do governo Lula: avanços e contradições. Revista ABET, v. 10, n. 2, p.30-54, jul./dez. 2011.

LEAL FILHO, R. de S. Tendências recentes nos mercados de trabalho: limites das propostas de flexibilização e regulamentação. 1994. Dissertação (Economia) Instituto de Economia - Universidade Estadual de Campinas, Campinas.

MATTOS, F. Flexibilização do trabalho: Sintomas da Crise. São Paulo: ANNABLUME, 2009. 270 p.

OLIVEIRA, C. A. Contrato Coletivo e Relações de Trabalho no Brasil. In. OLIVEIRA, C. A et.al. (Orgs.). O Mundo do Trabalho: crise e mudanças no final do século. São Paulo: Scritta, 1994.

PAEZ, C. S.; SANTOS, A. L. Diverging paths in development: Brazil and Mexico. In: Crisis: Causes, prospects and alternatives. International Journal of Labour Research. Genebra. v. 3, n. 1, p. 115-132, 2011.

PASTORE, J. A flexibilidade do trabalho. São Paulo: LTr, 1994.

POCHMANN, M. A década dos mitos: o novo modelo econômico e a crise do trabalho no Brasil. São Paulo: Contexto, 2001.

QUADROS, W. A Evolução recente da estrutura social brasileira. Texto de Discussão, IE/UNICAMP, n. 148, 2008. SANTOS. A. L. Trabalho em Pequenos negócios no Brasil. São Paulo: LTr; Campinas: CESIT/IE, 2013.

SARTI, F; HIRATUKA, C. Desenvolvimento industrial: oportunidades e desafios futuros. Texto de Discussão, IE/ UNICAMP, n. 187, 2011.

SENNETT, R. A corrosão do caráter: conseqüências pessoais do trabalho no novo capitalismo. Rio de Janeiro: Editora Record, 1999.

URIATE, O. E. La flexibilidad. Montevideo: Fundación de Cultura Universitaria, 2000.

ZYLBERSTAJN, H. A Reforma do Mercado de Trabalho e a Convenção 87. São Paulo: FEA/USP e FIPE. (Mimeo), 1998. 


\section{RESUMPTION OF DEVELOPMENT AND THE REGULATION OF THE LABOR MARKET IN BRAZIL}

\author{
Paulo Eduardo de Andrade Baltar \\ José Dari Krein
}

This article establishes a relationship between the dynamics of contemporary capitalism in Brazil and the challenges of discussing public regulation of labor. The debate in Brazil takes into consideration these aspects: 1) changes to contemporary capitalism have led to implications which are unfavorable to public regulation of labor and to collective action by workers; 2) the resurgence of economic growth has made it possible to redefine the terms of the debate on labor in Brazil; 3) the current crisis brings into discussion the possibility of the State taking a more active role in economic development; 4) demographic trends have increased the weight of the adult EAP, which has implications in the functioning of the labor market. The positions are polarized thus: 1) the defense of structuring the work market with implications in the quality of social relations; 2) business affirmation, which stresses the need for more flexibility in hiring, duties and pay for work.

Key words: Labor. Regulation. Economy and development. Flexibilization.

\section{LA REPRISE DU DÉVELOPPEMENT ET LA RÉGULATION DU MARCHÉ DU TRAVAIL AU BRÉSIL}

\author{
Paulo Eduardo de Andrade Baltar \\ José Dari Krein
}

L'article établit une relation entre la dynamique du capitalisme contemporain au Brésil et les défis concernant la discussion pour une régulation publique du travail. Le débat au Brésil prend en considération les aspects suivants: 1) les transformations du capitalisme contemporain démontrent avoir des implications négatives pour la régulation publique du travail et pour l'action collective des travailleurs; 2) la reprise de la croissance économique a permis de redéfinir les termes du débat sur le travail au Brésil; 3) la crise actuelle remet en question la capacité de l'Etat à jouer un rôle plus actif dans le développement de l'économie; 4) les tendances démographiques sont en train d'augmenter le poids de la population économiquement active adulte, ce qui a des conséquences sur le fonctionnement du marché du travail. Les positions se situent entre deux tendances: 1) la défense d'une structuration du marché du travail avec des implications pour la qualité des relations sociales; 2 ) la déclaration des entreprises qui met en évidence le besoin d'une plus grande flexibilité au niveau des contrats, de f'utilité et de la rémunération du travail.

Mots-CLÉs: Travail. Régulation. Économie et développement. Flexibilité.

Paulo Eduardo de Andrade Baltar - Doutor em Ciência Econômica. Professor Associado da Universidade Estadual de Campinas. Tem experiência na área de Economia, com ênfase em Economia do Bem-Estar Social. Entre várias publicações em periódicos e livros, é coorganizador (com José Dari Krein e Carlos SALAS) de Economia e trabalho: Brasil e México. 1a ed. São Paulo: LTr, 2009. v. 7. 271p. Universidade Estadual de Campinas, Instituto de Economia, Centro de Estudos Sindicais e de Economia do Trabalho.

José Dari Krein - Doutor em Economia Social e do Trabalho. Professor da Universidade Estadual de Campinas - UNICAMP. Tem experiência na área de Economia, com ênfase em Emprego, Relações de Trabalho, Sindicalismo e Negociação Coletiva, atuando principalmente nos seguintes temas: flexibilização, legislação trabalhista, reforma, sindicalismo, trabalho, reestruturação produtiva, emprego, tecnologia, trabalho, salário mínimo e desenvolvimento econômico. Publicou, entre artigos e livros, As relações de trabalho na era do neoliberalimo no Brasil. 1ª. ed. São Paulo: LTR, 2012, v. 8, 319p. Universidade Estadual de Campinas, Instituto de Economia. 